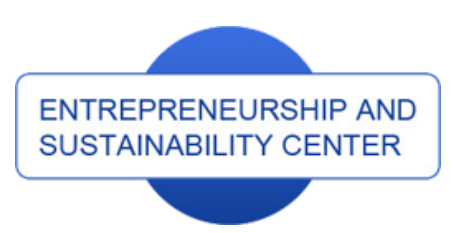

Publisher

http://jssidoi.org/esc/home enterprise

europe

network

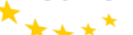

Business Support on Your Doorstep

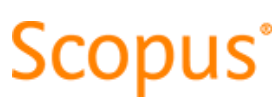

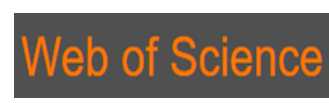

1) Clarivate

Analytics

\title{
MODELS FOR THE INTERACTION BETWEEN SPACE SERVICES PROVIDERS AND MANUFACTURERS OF SPACE VEHICLES
}

\author{
Dmitry Ivanov ${ }^{1}$, Elena Belyaeva ${ }^{2}$, Anastasia Kurilova ${ }^{3}$, Elena Popkova ${ }^{4}$ \\ ${ }^{1,2}$ Samara National Research University, 34, Moskovskoye shosse, Samara, Russia \\ ${ }^{3}$ Tolyatti State University, 14, Belorusskaya St., Tolyatti, Russia \\ ${ }^{4}$ Volgograd State Technical University, 2, Volgograd State Technical University, 28, Lenina Ave. Volgograd, Russia

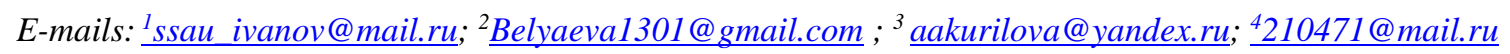

Received 15 February 2018; accepted 20 April 2018; published 30 June 2018

\begin{abstract}
The authors have formed the space market structure which is distinguished by the junctional formation of the summed demand for a product or service between the participants at the same stage, which serves as a basis for the formation of demand at the next stages. The peculiarities of participants' interaction on the space services market are associated with incomplete awareness. It is advisable to use the methodological approach considered in the theory of contracts in the case of asymmetric information to develop models of interaction between market participants. Thus, based on the theory of contracts and taking into account the specifics of interaction in this article the authors have described the models for the generation of an optimal contract for the manufacturer of space vehicles and space services providers. The models are presented for the cases with symmetric and asymmetric information. As a result of solution of the task for the generation of an optimal contract, such parameters of the contract as satellite performance, the price of its information throughput unit, as well as the cumulative indicator of its technical and operational characteristics can be found in the course of interaction between these participants of the space market. The determined parameters of the contract allow maximizing the profit of the manufacturer of space vehicles.
\end{abstract}

Keywords: decision model; contract theory; world space market; generation of an optimal contract; information symmetry; information asymmetry

Reference to this paper should be made as follows: Ivanov, D.; Belyaeva, E.; Kurilova, A.; Popkova, E. 2018. Models for the interaction between space services providers and manufacturers of space vehicles, Entrepreneurship and Sustainability Issues 5(4): 846-857. https://doi.org/10.9770/jesi.2018.5.4(10)

JEL Classifications: C70, L11, L14

\section{Introduction}

The volume of the world space market has increased almost 3 times for the last decade (Bocindzer 2017). A progressively large income share falls on commercial sector of the space market, in particular, on the space services segment. New market branches emerge which can open new opportunities for the economies of different 
countries. In addition, space services and goods become more affordable to the consumers, the growing competition between the participants of the space market forces them to develop new technological solutions to improve the quality of goods and services, as well as reduction in their value. The obvious trend of commercialization of the space market leads to the need of formulation of the models of interaction between the economic operators in each segment of this market. The space market is very specific; one of its features is the closed nature of information about its participants and the interaction between them in the context of an individual contractual relationship. This is precisely why the development of the models of interaction between the participants of the space market is expedient based on the contract theory.

The segmentation principle of the world space market is based on the data which was published in the reports of Satellite Industry Association (e.g. SIA, 2017). The models for the generation of an optimal contract between the manufacturer of space vehicles and the space services providers are based on the models of adverse selection of the two types of operators in the context of the contract theory (Borch 1962; Balbás et al. 2013, 2014; Bossaerts et al. 2010; Ardalan et al. 2017)

A model for the case of availability of asymmetric information involves finding the optimal contract by imposing the incentive restrictions, described in the works (Nash 1950; Kurz, Hart 1982). Utility functions for the satellite service providers are selected in such a way that Spence-Mirrlees condition (strict single crossing condition) was met for them (Araujo, Moreira 2010).

\section{Main part}

Space industry market can be classified into the following segments in terms of goods and services: manufacturing of space vehicles, manufacturing and operation of ground equipment, provision of launch services and manufacturing of launch vehicles, as well as provision of satellite services. Contractual relationship emerge both inside of each segment of the space market and between the segments.

Figure 1 presents the space market structure.

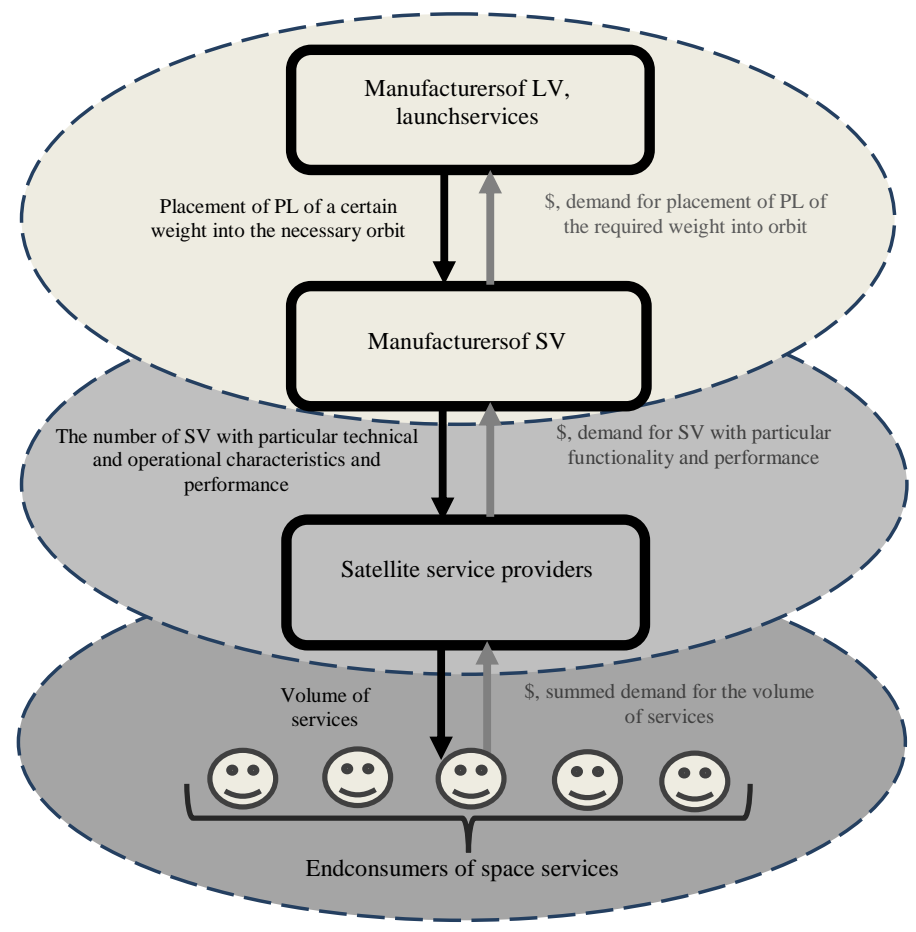


Fig 1. Space market structure.

(PL - payload, LV - launch vehicle, SV - space vehicle)

Source: https://www.roscosmos.ru/media/files/docs/2017/SpAsBus/1_bocindzer.euroconsult.-.roscosmos.1.ru.pdf

On a large scale, the interaction between the participants of the space market analyzed through the prism of generation of economic contracts between pairs "customer-performer", can be depicted in the form of three stages. The first stage describes the interaction between the satellite service providers and the end consumers. It is at this stage where a demand for a particular volume of services is formed, which subsequently imposes the areas of work to the following market stages. When an economic contract is generated at this stage, the satellite service provider provides a certain volume of services of a particular type to the end consumers, setting a price which depends on several factors (costs, market situation, consumer type, etc.). This range of satellite services, formed based on the demand of the end consumers, becomes the basis for the determination of the number of space vehicles required for satisfying the summed demand of the end consumers of space services and their technical and operational characteristics at the next stage. The second stage describes the interaction between the satellite service providers and the manufacturers of space vehicles: while some make an order for the performance of a specific technical task, the others offer to perform it for a certain price. Space vehicles of a certain weight, which are required to be placed into orbit, will be developed during the placement into orbit at the second stage. Thus, the need to place the required payload into a particular orbit by means of launch vehicles arises at the third stage, which is met through the conclusion of a commercial contract for the development of a launch vehicle and its launch.

Thus, the above scheme is representative of the entire process of functioning of the space market: from the starting point - the summed demand of the population for space services - to the final point - the launch and maintenance of an on-orbit space vehicle. In 2017, the volume of commercial sector of the world space market amounted to 250 billion USD (Figure 2) (Bocindzer 2017). 


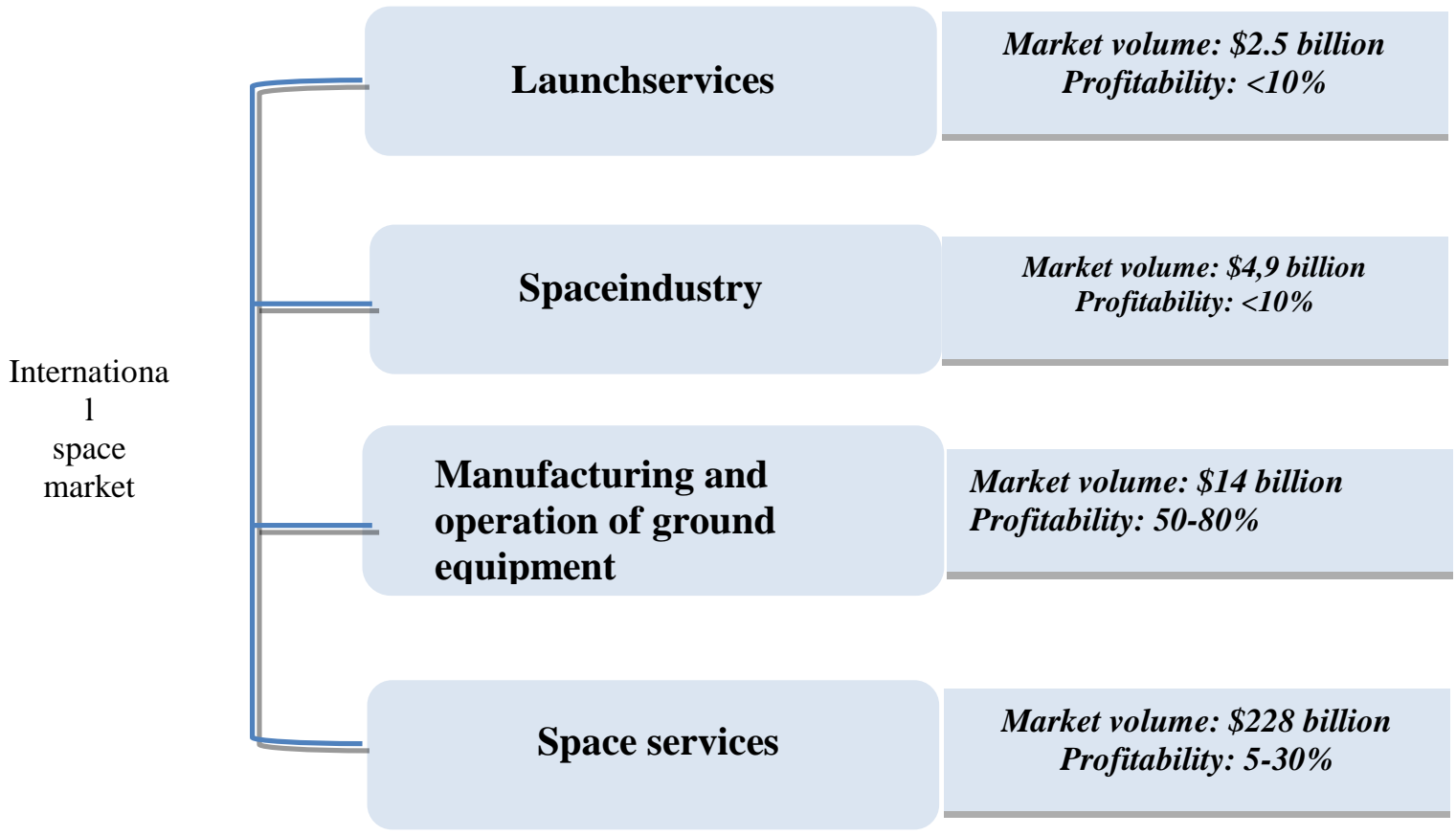

Fig 2. Volumes of the segments of the international space market in 2017

Source: https://www.roscosmos.ru/media/files/docs/2017/SpAsBus/1 bocindzer.euroconsult.-.roscosmos.1.ru.pd

The space services segment is the most significant: its income in 2017 amounted to $91 \%$ of the total income of the world space market. The number of participants of this segment of the space market is the largest at the moment: 
The International Journal

ENTREPRENEURSHIP AND SUSTAINABILITY ISSUES

ISSN 2345-0282 (online) http://jssidoi.org/jesi/

2018 Volume 5 Number 4 (June)

http://doi.org/10.9770/jesi.2018.5.4(10)

there are about 5000 companies in it. The cost effectiveness according to EBITDA (Earnings before interest, taxes, depreciation and amortization) in this segment reaches $30 \%$. About 50 companies are engaged in the sector of manufacturing and operation of ground equipment, about 30 companies are engaged in space industry sector, and about 10 companies are engaged in the launch services sector (Bocindzer 2017).

Thus, at each stage of the chain of formation of contractual relationship between the participants of the space market, the subject of the contract can be various parameters of a good or service which the customer (consumer) intends to receive. For example, at the stages of interaction between a company engaged in manufacturing of space vehicles and a space services provider the subject of the contract can be a particular number of space vehicles with functionality required by the provider. In order to generate the contract, the manufacturer of space vehicles faces the task of maximizing its profits through the identification of the value of satellite for the buyer (type of the buyer), apart from the task of formation of base cost of a project of development of space vehicle, because in this case there is an opportunity to increase the price for those types of buyers who are willing to pay more for the satellite. Thus, there arises a task of simulation of interaction of economic operators of the space market both in the context of symmetric information, when the type of the buyer is known to the manufacturer of satellites, and asymmetric information, when such information is not available to the buyer. In order to formulate such a model, one of the options may include the application of a vehicle of the contract theory, which allows to take into account the possible availability of information asymmetry in the market and to introduce a mechanism for identification of the types of space services providers in the model.

Let's consider a block diagram of interaction of participants of one of stages of the chain of formation of contractual relationship: the companies engaged in manufacturing of space vehicles and space services providers. In this case, pursuant to the terminology from the contract theory, the manufacturer of space vehicles is a principal, and the buyers of its products are operators, since the information about providers which is available to them is not available to the manufacturer: the manufacturers of space vehicles have no clear vision of the true value of satellites for the providers, or, in other words, of the maximum amount that a provider is willing to pay for a space vehicle to be purchased. We'll define this parameter as $\theta$, which will denote the type of the customer that, for example, in the context of the participants of the space market under consideration, can depend on the kind of further use of the satellite: commercial or non-commercial. Let's consider the simplified situation when two providers - $\theta_{1}$ and $\theta_{2}$ - refer to the manufacturer of space vehicles. The higher the ratio, the higher is the type of provider, which means it is willing to spend the greater amount on the purchase of the satellite. When ordering a satellite, the provider is interested in $x_{i}$ - it is the satellite performance (the amount of information required for the provider of $i$-type to satisfy the demand of the consumers of the space market or for own needs), as well as $\eta_{i}$ - a cumulative indicator of technical and operational characteristics generated by the manufacturer of space vehicles based on the requirements of the provider of $i$-type (Boonen 2016). The manufacturer of satellites, having received the information about the necessary characteristics, calculates the estimated costs for such a project and then offers the contract to the customer $\left(p_{i}, x_{i}, \eta_{i}\right)$, where $p_{i}$ is the cost of the conditional information throughput unit for the provider of $i$-type. The usefulness of the first customer is described by function $u_{1}\left(x_{1}, \eta_{1}, T_{1}\right)=\theta_{1} v_{1}\left(x_{1}, \eta_{1}\right)-T_{1}$, where $v_{l}\left(x_{1}, \eta_{1}\right)$ is the estimated monetary value of the satellite buyer with a performance of $x_{1}$ and a cumulative indicator of technical and operational characteristics $\eta_{1}$, $v_{1}\left(x_{1}\right)=a_{1} x_{1}^{2}+b_{1} x_{1}+m_{1} \eta_{1}^{2}+n_{1} \eta_{1}$; T1 is the costs of the first customer for the total information throughput to be purchased, where $T_{1}=p_{1}\left(1+\eta_{1}\right) x_{1}$.

The usefulness of the first customer is described by function $u_{2}\left(x_{2}, \eta_{2}, T_{2}\right)=\theta_{2} v_{2}\left(x_{2}, \eta_{2}\right)-T_{2}$, where $v_{2}\left(x_{2}, \eta_{2}\right)$ is the estimated monetary value of the satellite purchase provider with a performance of $x_{2}$ and a cumulative indicator of technical and operational characteristics $\eta_{2}, v_{2}\left(x_{2}\right)=a_{2} x_{2}^{2}+b_{2} x_{2}+m_{2} \eta_{2}^{2}+n_{2} \eta_{2} ; T_{2}$ is the costs of the 
second customer for the total information throughput to be purchased, where $T_{2}=p_{2}\left(1+\eta_{2}\right) x_{2}$. The costs of the manufacturer of space vehicles for the information throughput unit amount to $c$.

Let's simulate two cases: in the first case, we will refer to symmetric information, when the type of the satellite buyer is known to the manufacturer of space vehicles, and, based on this information, he takes a decision on what satellite performance and its cumulative indicator of technical and operational characteristics it can offer based on the customer's requests, and how much the information throughput unit of such satellite will cost. Asymmetric information is considered in the second case, when the manufacturer of space vehicles is not able to differentiate the satellite buyers and thus is dorced to employ a principle of identification of the type of provider in order to determine the optimal menu of contracts in the form of $\left(x_{1}{ }^{*}, p_{1}{ }^{*}, \eta_{1}{ }^{*}\right)$ and $\left(x_{2}{ }^{*}, p_{2}{ }^{*}, \eta_{2}{ }^{*}\right)$ for each type of it.

Both satellite service providers solve the task of maximizing their own usefulness for themselves: $\theta_{i} v_{i}\left(x_{i}, \eta_{i}\right)-T_{i} \rightarrow \max _{x_{i}, \eta_{i}}, i=1,2$ (Aase 2009). When substituting expressions of the estimated monetary value of the satellite, purchase provider and its costs for the purchase of a space vehicle, we obtain the following target function of the first provider: $\theta_{1}\left(a_{1} x_{1}^{2}+b_{1} x_{1}+m_{1} \eta_{1}^{2}+n_{1} \eta_{1}\right)-p_{1}\left(1+\eta_{1}\right) x_{1} \rightarrow \max _{x_{1}, \eta_{1}}$. In order to find the cumulative indicator of technical and operational characteristics of the satellite and its performance, the provider of the first type must solve the system of equations - first-order conditions by $x_{1}$ and $\eta_{1}$ (Osborne, Rubinstein 1964) (1)-(12):

$\left\{\begin{array}{l}\frac{\partial u_{1}}{\partial x_{1}}=2 \theta_{1} a_{1} x_{1}+\theta_{1} b_{1}-p_{1}\left(1+\eta_{1}\right)=0 \\ \frac{\partial u_{1}}{\partial \eta_{1}}=2 \theta_{1} m_{1} \eta_{1}+\theta_{1} n_{1}-p_{1} x_{1}=0\end{array}\right.$

Let's express $\eta_{1}$ from the second equation:

$\eta_{1}=\frac{p_{1} x_{1}-\theta_{1} n_{1}}{2 \theta_{1} m_{1}}$

Further, we insert the expressed $\eta_{1}$ into the first equation of the system (1) and determine the optimal performance indicator of the satellite $x_{1} *$ for the provider of the first type:

$x_{1}^{*}=\frac{\theta_{1}\left(2 m_{1} p_{1}-2 \theta_{1} b_{1} m_{1}-p_{1} n_{1}\right)}{4 \theta_{1}^{2} a_{1} m_{1}-p_{1}^{2}}$

Now the determined optimal satellite performance (3) is inserted into expression (2), and the optimal cumulative indicator of technical and operational characteristics of the satellite is determined:

$\eta_{1}^{*}=\frac{p_{1} \theta_{1}\left(2 m_{1} p_{1}-2 \theta_{1} b_{1} m_{1}-p_{1} n_{1}\right)-\theta_{1} n_{1}\left(4 \theta_{1}^{2} a_{1} m_{1}-p_{1}^{2}\right)}{2 \theta_{1} m_{1}\left(4 \theta_{1}^{2} a_{1} m_{1}-p_{1}{ }^{2}\right)}$

A set of equations drawn up for the provider of the second type after differentiation of its target function, is solved in a similar way $\theta_{2}\left(a_{2} x_{2}^{2}+b_{2} x_{2}+m_{2} \eta_{2}^{2}+n_{2} \eta_{2}\right)-p_{2}\left(1+\eta_{2}\right) x_{2} \rightarrow \max _{x_{2}, \eta_{2}}$ :

$$
\left\{\begin{array}{l}
\frac{\partial u_{2}}{\partial x_{2}}=2 \theta_{2} a_{2} x_{2}+\theta_{2} b_{2}-p_{2}\left(1+\eta_{2}\right)=0 \\
\frac{\partial u_{2}}{\partial \eta_{2}}=2 \theta_{2} m_{2} \eta_{2}+\theta_{2} n_{2}-p x_{2}=0
\end{array}\right.
$$

Let's express $\eta_{2}$ from the second equation of the system (5): 
$\eta_{2}=\frac{p_{2} x_{2}-\theta_{2} n_{2}}{2 \theta_{2} m_{2}}$

Further, expression (6) is inserted into the first equation of the system (5) and the optimal performance indicator of the satellite $x_{2} *$ is determined for the provider of the second type:

$x_{2} *=\frac{\theta_{2}\left(2 m_{2} p_{2}-2 \theta_{2} b_{2} m_{2}-p_{2} n_{2}\right)}{4 \theta_{2}^{2} a_{2} m_{2}-p_{2}^{2}}$

In order to determine the cumulative indicator of technical and operational characteristics of the satellite for the provider of the second type, equation (7) is inserted into (6) and expressed as $\eta_{2} *$ :

$\eta_{2} *=\frac{p_{2} \theta_{2}\left(2 m_{2} p_{2}-2 \theta_{2} b_{2} m_{2}-p_{2} n_{2}\right)-\theta_{2} n_{2}\left(4 \theta_{2}^{2} a_{2} m_{2}-p_{2}{ }^{2}\right)}{2 \theta_{2} m_{2}\left(4 \theta_{2}{ }^{2} a_{2} m_{2}-p_{2}{ }^{2}\right)}$

The providers' demand for the satellites $D_{i}$ is described by equations where xcmaxis the maximum satellite performance, for each individual customer:

$$
\begin{aligned}
& D_{1}=\left\{\begin{array}{l}
\frac{\theta_{1}\left(2 m_{1} p_{1}-2 \theta_{1} b_{1} m_{1}-p_{1} n_{1}\right)}{\left(4 \theta_{1}^{2} a_{1} m_{1}-p_{1}{ }^{2}\right) x_{c}{ }^{\max }}, 0 \leq p_{1} \leq \theta_{1} \\
0, p_{1}>\theta_{1}
\end{array}\right. \\
& D_{2}=\left\{\begin{array}{l}
\frac{\theta_{2}\left(2 m_{2} p_{2}-2 \theta_{2} b_{2} m_{2}-p_{2} n_{2}\right)}{\left(4 \theta_{2}^{2} a_{2} m_{2}-p_{2}{ }^{2}\right) x_{c}{ }^{\max }}, 0 \leq p_{2} \leq \theta_{2} \\
0, p_{2}>\theta_{2}
\end{array}\right.
\end{aligned}
$$

The task of the manufacturer of space vehicles consists in maximization of its profit $\Pi_{i}$ from the order of provider of each type: $\Pi_{i}=\left(p_{i}-c\left(1+\eta_{i}\right)\right) \cdot D_{i}\left(p_{i}\right) \rightarrow \max _{p_{i}}$

Demand expressions (9) and (10) respectively should be inserted into the target function of the manufacturer of space vehicles for each type of provider, after which it should be differentiated according to the price. Thus, the task of the manufacturer of space vehicles for the provider of the first type will be as follows:

$$
\Pi_{1}=\left(p_{1}-c\left(1+\eta_{1}\right)\right) \cdot \frac{\theta_{1}\left(2 m_{1} p_{1}-2 \theta_{1} b_{1} m_{1}-p_{1} n_{1}\right)}{\left(4 \theta_{1}^{2} a_{1} m_{1}-p_{1}^{2}\right) x_{c}^{\max }} \rightarrow \max _{p_{1}}
$$

For the provider of the second type:

$$
\Pi_{2}=\left(p_{2}-c\left(1+\eta_{2}\right)\right) \cdot \frac{\theta_{2}\left(2 m_{2} p_{2}-2 \theta_{2} b_{2} m_{2}-p_{2} n_{2}\right)}{\left(4 \theta_{2}^{2} a_{2} m_{2}-p_{2}^{2}\right) x_{c}^{\max }} \rightarrow \max _{p_{2}}
$$

The obtained equation has no analytical solution during differentiation. In this case, the known numerical methods can be used for determination of extremum of functions (Balbás, A., Balbás, B., Balbás, R.). As a result, the optimal costs of the conditional information throughput unit will be obtained for the providers of the first type and the second type $p_{1} *$ and $p_{2} *$ respectively.

Thus, the task which was considered in the above statement has the following stages of solution for the case $k$ of providers:

1. A task for each provider of $i$-type is generated:

$$
u_{i}=\theta_{i} v_{i}\left(x_{i}, \eta_{i}\right)-T_{i} \rightarrow \max _{x_{i}, \eta_{i}}, i=\overline{1, k}
$$


2. A system of equations is solved - first-order conditions by $x_{i}$ and $\eta_{i \cdot}\left\{\begin{array}{l}\frac{\partial u_{i}}{\partial x_{i}}=0 \\ \frac{\partial u_{i}}{\partial \eta_{i}}=0\end{array}, i=\overline{1, k}\right.$

As a result of solution of the system of equations, the optimal cumulative indicators of technical and operational characteristics of satellite $\eta_{i}^{*}$ and its performance indicator $x_{i}^{*}$ are determined.

3. A demand for satellites of each provider of i-type is formed:

$$
D_{i}=\left\{\begin{array}{l}
\frac{x_{i}}{x_{c}{ }^{\max }}, 0 \leq p_{i} \leq \theta_{i} \\
0, p_{i}>\theta_{i}
\end{array}, i=\overline{1, k}\right.
$$

4. With due consideration of determined optimal values $x_{i}^{*}$ and $\eta_{i}{ }^{*}$ the target function of the manufacturer of space vehicles is registered: $\Pi_{i}=\left(p_{i}-c\left(1+\eta_{i}\right)\right) \cdot D_{i}\left(p_{i}\right) \rightarrow \max _{p_{i}}, i=\overline{1, k}$. The optimal value of price $p_{i} *$ is determined on the basis of extremum condition, namely the maximum target function of the manufacturer of space vehicles: $\frac{\partial \Pi_{i}}{\partial p_{i}}=0$. The expressions obtained determine the values of an individual cost of the conditional information throughput unit $p_{i}{ }^{*}$ for each provider of $i$ type.

Thus, the presented algorithm for solving the task of determining the optimal parameters of the contracts between the providers and the manufacturer of space vehicles makes it possible to generate an individual contract $\left(x_{i}^{*}, p_{i}{ }^{*}, \eta_{i}{ }^{*}\right)$ for each provider of i-type, taking into account the value of the satellite to be purchased.

If the information is asymmetric, the manufacturer of space vehicles can not determine the value of the satellite for a particular provider. As a result, the problem of adverse selection arises, when providers can hide their individual value of a space vehicle or adjust it in such a way as to obtain the satellites on more favorable terms with a higher performance. In such a situation, the task of the manufacturer of space vehicles will be to draw up such contract that would guarantee the inexpedience of selection of conditions designed for another type of provider (Asimit et al. 2017).

Thus, similar to symmetric information, the manufacturer of space vehicles offers the contracts of the following form: $\left(x_{1}{ }^{*}, p_{1}{ }^{*}, \eta_{1}{ }^{*}\right)$ and $\left(x_{2}{ }^{*}, p_{2}{ }^{*}, \eta_{2}{ }^{*}\right)$ to the customers. The concept of the contract with filtration of providers in the context of the contract theory involves the use of a principle of identification of their types. This principle consists in imposing the system of restrictions which forces the provider of a higher type to choose its own menu of contracts (Quiggin, Chambers 2009).

Thus, the task of the manufacturer of space vehicles will be as follows (13)-(16):

$$
\begin{aligned}
& \Pi=\pi\left(p_{1}\left(1+\eta_{1}\right) \mathrm{x}_{1}-c\left(1+\eta_{1}\right) x_{1}\right)+(1-\pi)\left(p_{2}\left(1+\eta_{2}\right)-c\left(1+\eta_{2}\right) x_{2}\right) \rightarrow \max _{p_{1}, p_{2}, x_{1}, x_{2}, \eta_{1}, \eta_{2}} \\
& \left\{\begin{array}{l}
\theta_{1}\left(a_{1} x_{1}^{2}+b_{1} x_{1}+m_{1} \eta_{1}^{2}+n_{1} \eta_{1}\right)-p_{1}\left(1+\eta_{1}\right) \geq 0 \\
\theta_{2}\left(a_{2} x_{2}^{2}+b_{2} x_{2}+m_{2} \eta_{2}^{2}+n_{2} \eta_{2}\right)-p_{2}\left(1+\eta_{2}\right) \geq 0 \\
\theta_{1}\left(a_{1} x_{1}^{2}+b_{1} x_{1}+m_{1} \eta_{1}^{2}+n_{1} \eta_{1}\right)-p_{1}\left(1+\eta_{1}\right) \geq \theta_{1}\left(a_{2} x_{2}^{2}+b_{2} x_{2}+m_{2} \eta_{2}^{2}+n_{2} \eta_{2}\right)-p_{2}\left(1+\eta_{2}\right) \\
\theta_{2}\left(a_{2} x_{2}^{2}+b_{2} x_{2}+m_{2} \eta_{2}^{2}+n_{2} \eta_{2}\right)-p_{2}\left(1+\eta_{2}\right) \geq \theta_{2}\left(a_{1} x_{1}^{2}+b_{1} x_{1}+m_{1} \eta_{1}^{2}+n_{1} \eta_{1}\right)-p_{1}\left(1+\eta_{1}\right)
\end{array}\right.
\end{aligned}
$$


Inequalities (13)-(14) are participation restriction conditions. Inequality (13) determines the inexpedience of withdraw from a bargain for the first provider, and (14) - for the second provider. Conditions (15)-(16) incentive compatibility restrictions - guarantee that both type of providers will choose the contracts offered by the manufacturer of space vehicles exactly for their type: the usefulness of own contract is higher than the usefulness of someone else's contract (Zhou et al. 2015).

Since the estimated monetary value of the satellite purchase provider of the first type is equal to or larger than zero $a_{1} x_{1}^{2}+b_{1} x_{1}+m_{1} \eta_{1}^{2}+n_{1} \eta_{1} \geq 0$ and the provider of the second type is ready to purchase the satellite for a higher price than the provider of the first type $\left(\theta_{2}>\theta_{1}\right)$, then

$$
\theta_{2}\left(a_{2} x_{2}^{2}+b_{2} x_{2}+m_{2} \eta_{2}^{2}+n_{2} \eta_{2}\right)-p_{2}\left(1+\eta_{2}\right) \geq \theta_{2}\left(a_{1} x_{1}^{2}+b_{1} x_{1}+m_{1} \eta_{1}^{2}+n_{1} \eta_{1}\right)-p_{1}\left(1+\eta_{1}\right) \geq
$$

$\theta_{1}\left(a_{1} x_{1}^{2}+b_{1} x_{1}+m_{1} \eta_{1}^{2}+n_{1} \eta_{1}\right)-p_{1}\left(1+\eta_{1}\right)$. If the participation restriction condition (13) is met as an equality, than the cost of the conditional information throughput unit can be increased in such a way that participation restrictions will be met at the same time, and the manufacturer of space vehicles will fatten its profits. Thus, condition (13) is met as an equality in the optimum. Similarly, incentive compatibility condition (15) turns into equality. Thus, since conditions (13) and (16) of the condition are effective, other conditions can be neglected (Aase, 2009) (17)-(18):

$$
\begin{aligned}
& \Pi=\pi\left(p_{1}\left(1+\eta_{1}\right) \mathrm{x}_{1}-c\left(1+\eta_{1}\right) x_{1}\right)+(1-\pi)\left(p_{2}\left(1+\eta_{2}\right)-c\left(1+\eta_{2}\right) x_{2}\right) \rightarrow \max _{p_{1}, p_{2}, x_{1}, x_{2}, \eta_{1}, \eta_{2}} \\
& \left\{\begin{array}{l}
\theta_{1}\left(a_{1} x_{1}^{2}+b_{1} x_{1}+n_{1} \eta_{1}^{2}+m_{1} \eta_{1}\right)-p_{1}\left(1+\eta_{1}\right) \geq 0 \\
\theta_{2}\left(a_{2} x_{2}^{2}+b_{2} x_{2}+n_{2} \eta_{2}^{2}+m_{2} \eta_{2}\right)-p_{2}\left(1+\eta_{2}\right) \geq \theta_{2}\left(a_{1} x_{1}^{2}+b_{1} x_{1}+n_{1} \eta_{1}^{2}+m_{1} \eta_{1}\right)-p_{1}\left(1+\eta_{1}\right)
\end{array}\right.
\end{aligned}
$$

Based on conditions (17)-(18), we shall express the costs of the information throughput unit of a space vehicle for both types of the satellite buyers:

$$
\begin{gathered}
p_{1}^{*}=\frac{\theta_{1}\left(a_{1} x_{1}^{2}+b_{1} x_{1}+m_{1} \eta_{1}^{2}+n_{1} \eta_{1}\right)}{\left(1+\eta_{1}\right) \mathrm{x}_{1}} \\
p_{2}^{*}=\frac{\theta_{2}\left(a_{2} x_{2}^{2}+b_{2} x_{2}+m_{2} \eta_{2}^{2}+n_{2} \eta_{2}\right)-\theta_{2}\left(a_{1} x_{1}^{2}+b_{1} x_{1}+m_{1} \eta_{1}^{2}+n_{1} \eta_{1}\right)+\frac{\theta_{1}\left(a_{1} x_{1}^{2}+b_{1} x_{1}+m_{1} \eta_{1}^{2}+n_{1} \eta_{1}\right)}{\left(1+\eta_{1}\right) x_{1}}}{\left(1+\eta_{2}\right) x_{2}}
\end{gathered}
$$

Further, the found expressions for the optimum price for a standard configuration of the satellite (19)-(20) are inserted into the target function of the manufacturer of space vehicles:

$$
\begin{aligned}
& \Pi=\pi\left(\frac{\theta_{1}\left(a_{1} x_{1}^{2}+b_{1} x_{1}+n_{1} \eta_{1}^{2}+m_{1} \eta_{1}\right)}{\left(1+\eta_{1}\right) x_{1}}-c\left(1+\eta_{1}\right) x_{1}\right)+(1-\pi)\left(\frac{\theta_{2}\left(a_{2} x_{2}^{2}+b_{2} x_{2}+m_{2} \eta_{2}^{2}+n_{2} \eta_{2}\right)-\theta_{2}\left(a_{1} x_{1}^{2}+b_{1} x_{1}+m_{1} \eta_{1}^{2}+n_{1} \eta_{1}\right)}{\left(1+\eta_{2}\right) x_{2}}+\right. \\
& \frac{\left.\left.\frac{\theta_{1}\left(a_{1} x_{1}^{2}+b_{1} x_{1}+m_{1} \eta_{1}^{2}+n_{1} \eta_{1}\right)}{\left(1+\eta_{1}\right) x_{1}}\right)-c\left(1+\eta_{2}\right) x_{2}\right) \rightarrow \max _{p_{1}, p_{2}, x_{1}, x_{2}, \eta_{1}, \eta_{2}}}{\left(1+\eta_{2}\right) x_{2}}
\end{aligned}
$$

Then a system of equations is solved - first-order conditions by $x_{1}^{*}, x_{2}{ }^{*}, \eta_{1}{ }^{*}, \eta_{2} *$ : 


$$
\left\{\begin{array}{l}
\frac{\partial \Pi}{\partial x_{1}}=0 \\
\frac{\partial \Pi}{\partial x_{2}}=0 \\
\frac{\partial \Pi}{\partial \eta_{1}}=0 \\
\frac{\partial \Pi}{\partial \eta_{2}}=0
\end{array}\right.
$$

This system of equations excludes analytical solution. Similar to symmetric information, the known numerical methods of solution can be used. As a result of solution, the optimal performance indicator of the satellite $x_{1} *$ and $x_{2} *$ as well as the cumulative indicator of its technical and operational characteristics $\eta_{1} *$ and $\eta_{2} *$ will be obtained for both types of providers in the context of asymmetric information.

Thus, the task of finding the optimal contracts for the two providers in the context of information asymmetry, considered in the above statement, has the following stages of solution for the case $k$ of providers:

1. The task of the manufacturer of space vehicles is formed, which consists in selection of menu of contracts $\left(x_{i}^{*}, p_{i}^{*}, \eta_{i}^{*}\right), \mathrm{i}=\overline{1, k}$, which maximizes its profit function:

$$
\Pi=\sum_{i=1}^{k} \pi_{i}\left(\mathrm{~T}_{i}-c\left(1+\eta_{i}\right) x_{i}\right)
$$

2. The restrictions of individual rationality for all i providers and incentive compatibility restrictions for all $i, j$ providers are set:

$\theta_{i} v_{i}\left(x_{i}, \eta_{i}\right)-T_{i} \geq 0$

$\theta_{i} v_{i}\left(x_{i}, \eta_{i}\right)-T_{i} \geq \theta_{i} v_{j}\left(x_{j}, \eta_{j}\right)-T_{j}$

The restrictions of individual rationality guarantee participation of providers in the contract process, while the incentive compatibility restrictions guarantee refusal of the provider of type $i$ from pretending to be the provider of type $j$.

If there is a strict single crossing condition (Spence-Mirrlees condition), the solution consists in setting the restriction of individual rationality as an equality for the lowest type of provider in the same manner as the incentive compatibility restriction for pairs $i$ and $i-1$ (Araujo, Moreira 2010). As a result, all providers, except the provider of the highest type, will receive less satellites than in the public optimum, and only the high-type provider will receive the effective number of satellites with such technical and operational characteristics which are the most relevant for it. If the strict single crossing condition is not met, the solution of the task will be very complicated due to the need of search through a great number of cases.

\section{Conclusions}

Thus, the authors have developed a scheme of the space market structure. This scheme implies that the determined parameters of the contract between the participants of the same stage in the course of formulation of interaction models can be used at the next stage, transforming into new parameters. For one of the described stages at which the generation of contract between the space services provider and the manufacturer of space vehicles is considered, a task of finding the optimal contract parameters in the context of symmetric and asymmetric information was simulated. The found parameters allow maximizing the profit of the manufacturer 
of space vehicles through identification of the type of providers that want to purchase the satellites. As a result, a contract will be offered to each type of space services provider, including the individual price of the information throughput unit of the satellite, performance, as well as its cumulative indicator of technical and operational characteristics.

\section{References}

Aase, K.K. 2009. The Nash bargaining solution vs. equilibrium in a reinsurance syndicate. Scandinavian Actuarial Journal, (3), pp. 219238. https://doi.org/10.1080/03461230802425834

Aase, K.K. 2017. Optimal insurance policies in the presence of costs. Risks, 5(3), p. 46. https://doi.org/10.3390/risks5030046

Araujo, A., Moreira, H. 2010. Adverse selection problems without the Spence-Mirrlees condition. Journal of Economic Theory, 145 (3), pp. 1113-1141. https://doi.org/10.1016/j.jet.2010.02.010

Ardalan, F.; Almasi, N. A.; Atasheneh, M. 2017. Effects of contractor and employer's obligations in buy back contracts: case study of oil exporting country. Entrepreneurship and Sustainability Issues 5(2), pp. 345-356. https://doi.org/10.9770/jesi.2017.5.2(13)

Asimit, A., V.; Bignozzi, V.; Cheung, K.C.; Hu, J.; Kim, E.S. 2017. Robust and Pareto optimality of insurance contracts. European Journal of Operational Research, 262, pp. 720-732. https://doi.org/10.1016/j.ejor.2017.04.029

Balbás, A., Balbás, B., Balbás, R. 2013. Good deals in markets with friction. Quantitative Finance, 13(6), pp. 827-836. https://www.tandfonline.com/doi/abs/10.1080/14697688.2013.780132

Balbás, B. Balbás, R. Balbás, A., 2014. Optimal reinsurance under risk and uncertainty. Insurance: Mathematics and Economics, 60 (2015), pp. 61-74. https://doi.org/10.1016/j.insmatheco.2014.11.001

Bocindzer S. 2017. "Space as business" ["Kosmoskakbiznes”], available at: https://www.roscosmos.ru/media/files/docs/2017/SpAsBus/1 bocindzer.euroconsult.-.roscosmos.1.ru.pdf.

Boonen, T.J. 2016. Nash equilibria of over-the-counter bargaining for insurance risk redistributions: The role of a regulator. European Journal of Operational Research, 250(3), pp. 955-965. https://doi.org/10.1016/j.ejor.2015.09.062

Borch, K. 1962. Equilibrium in a reinsurance market. Econometrica, 30 (1962), pp. 424-444. https://doi.org/10.2307/1909887

Bossaerts, P., Ghirardato, P., Guarnaschelli, S., Zame, W.R. 2010. Ambiguity in asset markets: Theory and experiment. Review of Financial Studies, 23(4), pp. 1325-1359. https://doi.org/10.1093/rfs/hhp106

Kurz, M., Hart, S. 1982. Pareto-optimal Nash equilibria are competitive in a repeated economy. Journal of Economic Theory, 28 (2), pp. 320-346. https://doi.org/10.1016/0022-0531(82)90064-3

Nash, J.F. 1950. Equilibrium points in n-person games. Proceedings of the National Academy of the USA, 36, pp. 48-49.

Nash, J.F. 1950. The bargaining problem. Econometrica, 18, pp. 155-162.

Osborne, M., Rubinstein, A. 1964. A Course in Game Theory. MIT Press Cambridge

Quiggin, J., Chambers, R.G. 2009. Bargaining power and efficiency in insurance contracts. GENEVA Risk and Insurance Review, 34 (1), pp. 47-73. https://doi.org/10.1057/grir.2008.15

SIA State of Satellite Industry Report. 2017. The Tauri group, 33 p., available at: https://www.sia.org/wp-content/uploads/2017/07/SIASSIR-2017.pdf

Zhou, R., Li, J.S.H., Tan, K.S. 2015. Modeling longevity risk transfers as Nash bargaining problems: Methodology and insights. Economic Modelling, 51, pp. 460-472. https://doi.org/10.1016/j.econmod.2015.08.019 


\author{
Dmitry IVANOV \\ ORCID ID: 0000-0003-0619-9340 \\ Elena BELYAEVA \\ ORCID ID: 0000-0002-0205-7209 \\ Anastasia KURILOVA \\ ORCID ID: 0000-0002-1943-5675 \\ Elena POPKOVA \\ ORCID ID:
}

Register for an ORCID ID:

https://orcid.org/register

\footnotetext{
Copyright (C) 2018 by author(s) and VsI Entrepreneurship and Sustainability Center

This work is licensed under the Creative Commons Attribution International License (CC BY).

http://creativecommons.org/licenses/by/4.0/

cC) (i) Open Access
} 